\title{
O sujeito psicótico e a função do delírio*1
}

Raquel Briggs*2

Doris Rinaldi*3

\begin{abstract}
Este trabalho aborda o conceito de delírio e sua função na estrutura psicótica. A psicanálise considera o delírio, por um lado, fenômeno elementar e, por outro, tentativa de cura, portador de uma verdade. O presente trabalho objetiva abordar a estruturação delirante, assim como a função da mesma para o sujeito paranoico, no sentido de situar a direção de tratamento na clínica da paranoia. A partir de um caso clínico e embasando-se nos conceitos da psicanálise, discute-se a função do mesmo para o sujeito. Leva-se em conta a invenção do sujeito para além do delírio, a partir de uma estabilização que, entretanto, não acontece sem ele.
\end{abstract}

Palavras-chave: Delírio, paranoia, direção de tratamento

${ }^{* 1}$ Artigo baseado na dissertação de mestrado intitulada UM sujeito mais além da estruturação delirante: a função do delírio e a direção de tratamento na psicose, defendida em 2012 no Programa de Pós-Graduação em Psicanálise da Universidade do Estado do Rio de Janeiro, elaborada por Raquel Coelho Briggs de Albuquerque e orientada pela Profa. Dra. Doris Luz Rinaldi.

*2 Universidade do Estado do Rio de Janeiro - UERJ (Rio de Janeiro, RJ, Br).

${ }^{* 3}$ Universidade do Estado do Rio de Janeiro - UERJ (Rio de Janeiro, RJ, Br). 


\section{ARTIGOS}

\section{Santo Roberto: um fragmento clínico}

Roberto está na casa dos trinta anos. Aos 18 levou um tiro no pescoço, que o deixou com sequelas marcantes no aparelho fonador e no aparelho respiratório, além de uma grande cicatriz. Estava trabalhando quando alguém mandou que chamasse um traficante, em uma favela próxima. Ele se recusou e o homem atirou nele. Mas essa é a versão contada pela família. Segundo ele mesmo, a polícia confundiu-o com um traficante, e por isso atirou nele.

A partir de então, Roberto nunca mais foi o mesmo.

Conheci Roberto anos depois, no Centro de Atenção Psicossocial, onde ele já era acompanhado há algum tempo. Aos poucos, ele foi me contando, desordenadamente, sua história: ele fazia chover. Era o responsável pelas chuvas do país. Abanando as mãos para o céu chamava as nuvens, ou as afastava, de acordo com a necessidade de chuva.

Mas o que o afligia era o que havia se dado oito anos antes quando, a partir de uma grande seca, faltou energia elétrica e o país enfrentou um "apagão". Embora essa "crise do apagão" tenha realmente ocorrido, em 2001 e 2002, com o racionamento "voluntário" de energia, nosso paciente nos conta sua própria versão: faltou luz e água em hospitais e escolas de todo o país, e ele começou a receber inúmeros telefonemas de mulheres, "tinha até mulher casada", e pedidos, inclusive da TV Globo, para que ele interviesse e mandasse chuva. Ameaçaram-no de morte, caso ele não fizesse chover. Era Robertinho pra cá, Robertinho pra lá... Você tinha que ver como me tratavam bem, até que eu mandei a chuva e todos desapareceram. Ninguém mais me ligou. Ninguém me agradeceu. Eu não recebi nem um obrigado.

E desde então Roberto teria ficado neste impasse: precisava fazer chover para que não o pegassem. Ele costumava ouvir muitas vozes que diziam, entre outras coisas, que os malandros iam pegá-lo. Os "malandros" queriam matá-lo, mas as mulheres ficavam de olho nele. Mas se eu morrer eles vão ver: nunca mais vai chover. 
Roberto nos proporciona um belo exemplo de delírio psicótico e de como este delírio está ligado a sua posição em relação ao Outro. O delírio de Roberto constitui sua história, o localiza no mundo e explica "o porquê" de ele ser tão visado: de quererem matá-lo. Além disso, permite a Roberto sair de uma posição passiva em direção a uma posição ativa: aquele que faz chover. Com tantas funções importantes para este sujeito, seria suficiente definir este delírio apenas como uma patologia primária, como tantas vezes o faz a psiquiatria? Na sua clínica foi possível acompanhar os efeitos que teve sobre ele a sua estruturação delirante - como Lacan (1955-1956/2002) a chama em seu seminário dedicado às psicoses. Algumas conquistas, precárias, mas importantes, puderam ser alcançadas. Uma delas diz respeito a uma espécie de resolução que Roberto criou para o conflito da chuva: certa vez disse que tinha deixado a chuva por conta de Deus, pois o pastor da igreja disse para "não passar na frente de Deus". De outra feita, Roberto disse que agora a anja P1 o estava ajudando: ela estava tomando conta da chuva. E ele, Santo Roberto, que já tinha feito bastante coisa em favor do mundo, agora ia aproveitar a vida: comer do bom e do melhor.

\section{Um breve histórico sobre o delírio}

O termo delírio surge no século XVI, originado da palavra latina lira, que significa sulco (do arado). Logo, de-liro, surge como aquilo que está fora do sulco, fora do caminho reto da razão. A palavra delírio se referia, assim, aos mais diversos erros de razão, sejam os do comportamento, do juízo ou da percepção. Dessa forma, entre as mais diversas patologias que poderiam ser descritas como delírio, estava, por exemplo, a vertigem, que leva ao erro de fazer o sujeito pensar que o mundo está girando (Foucault, 1987/2005).

Com a separação cartesiana entre as substâncias extensa e pensante, a doença mental passou a ser questionada em sua origem. Como sintomas mentais poderiam ser causados por doenças físicas e vice-versa? (Berrios, 2011). Os estados delirantes febris (delirium) não mais poderiam ser considerados - como o eram desde o século V a.C. - uma perturbação da alma de origem orgânica. Portanto, nesse momento histórico, os estudiosos se dividem em dois grandes grupos. $\mathrm{O}$ primeiro, sob a influência de John Locke, acreditava que os delírios eram causados por um erro da sensopercepção, portanto, uma função corporal (Foucault, 1987/2005). Sob a justificativa de que a alma seria imutável, a doença só poderia ser orgânica (Berrios, 2006).

O segundo grupo acreditava que o delírio diria respeito ao adoecimento da alma, sendo, portanto, um erro de julgamento. 


\section{ARTIGOS}

Assim, no século XIX, alguns estudiosos da loucura, considerando a origem do erro na sensopercepção, consideravam o delírio análogo aos sonhos, acreditando que sua evolução seria tão mutável e variável como os últimos; enquanto outros, apostando no erro de julgamento, começam a tentar circunscrever os delírios segundo um modo de evolução interna que lhes seria próprio. É aí que surgem as primeiras nosologias, como o delírio crônico.

O próprio Freud (1892-1894/2006a) nos lembra que a escola alemã conservou a tendência a uma interpretação fisiológica do quadro clínico e da inter-relação dos sintomas, diferente da escola francesa, que se dedicava ao estudo evolutivo dos delírios. No "Prefácio à tradução alemã das Conferências de terça-feira de Charcot", Freud (1892-1894/2006a) expressa sua preferência pela abordagem da psiquiatria francesa: "A observação clínica dos franceses, indubitavelmente, ganha em autossuficiência, no sentido de que relega a plano secundário os critérios relativos à fisiologia" (p. 176).

Diversos psiquiatras da corrente francesa, como Guislam, Griesinger (alemão, influenciado por Guislam), Falret, Lasegue, Magnan e Kraepelin, estudaram e dividiram o então chamado delírio crônico em fases segundo a evolução observada (Bercherie, 1989). Magnan (1835-1916), por exemplo, sugere a divisão em quatro períodos: um primeiro período, de incubação e inquietude. Um segundo, de perseguição e sistematização. Um terceiro período, de grandeza, no qual as ideias de grandeza apareceriam por dedução lógica e, um quarto período, de demência.

Desse modo, é a chamada corrente francesa da psiquiatria que influenciará largamente o pensamento freudiano em torno do delírio, como veremos. Enquanto será a corrente alemã que influenciará a concepção da chamada psiquiatria moderna em torno do delírio. O psiquiatra francês Henri Ey (1900-1977), por exemplo, funda sua clínica sobre os níveis da desestruturação da consciência e não sobre a investigação de mecanismos psíquicos específicos do delírio, o que o levou a retomar a noção de delírio como um fenômeno desestruturado: "o delírio não se desenvolve como um cristal ou como uma semente, e não está condicionado por uma estrutura elementar que o determine" (Ey, 1974, p. 522).

São noções tais como as de Henri Ey que foram passando a predominar na psiquiatria, chegando soberanas aos manuais psiquiátricos e livros de psicopatologia atuais: uma conceituação descritiva, com a qual se chega à definição de delírio como juízo patologicamente falso (Dalgalarrondo, 2008). Frequentemente acrescenta-se à definição atual de delírio três características descritivas, definidas por Jaspers, em 1913: convicção extraordinária (certeza subjetiva), impossibilidade de remoção da ideia pela experiência, e conteúdo impossível. Tais definições, por serem descritivas e não estruturais, se mostram bastante limitadas, uma vez que não permitem avançar na questão da função do delírio para o sujeito. É assim que Lacan, contemporâneo e amigo de Henri Ey, instala, a partir da década de 1930, um 
embate teórico com o mesmo: Lacan (1998) aposta, tal qual Freud, na psicogênese da loucura, enquanto Henri Ey aposta na organogênese da mesma — sem qualquer estrutura ou influência do psiquismo.

Enfim, a psicanálise freudiana se insere neste contexto, anterior ao embate referido, com seus primórdios no final do século XIX e seu desenvolvimento no início do século XX. Apostando na psicogênese herdada da escola francesa, Freud insere, inicialmente, a paranoia no campo das neuroses, isto é, uma enfermidade que tem suas origens em conflitos psíquicos. Posteriormente, desenvolve uma teoria que tenta explicar a função do delírio para o sujeito, assim como o mecanismo específico da psicose.

\section{O delírio como tentativa de cura e como portador de uma verdade histórica}

Nos primeiros textos freudianos podemos ver o termo delírio aparecer em inúmeras situações, independente de ser um caso de neurose ou psicose. Entretanto, ao longo de sua obra, o delírio aparece cada vez mais atrelado à estrutura da psicose.

Em sua análise da obra "Delírios e sonhos na Gradiva de Jensen", Freud (1907/2006d) traz, sob o nome de delírio, a fantasia e os devaneios neuróticos de um jovem. Fantasia esta, muito próxima de um sonho, inclusive no sentido da representação da realização de um desejo recalcado. Mas muito próxima também da definição psicopatológica de delírio que, como disse Freud, chegava a "influenciar suas ações" (p. 25).

Dessa forma, em 1907, Freud ainda utiliza uma definição fenomenológica do delírio próxima ao sonho, como o próprio título da obra indica e, consequentemente, da noção de representação do desejo inconsciente.

Mas em 1911, ao escrever o "Caso Schreber", Freud apresenta uma nova concepção de delírio que o articula estreitamente à paranoia, ${ }^{1}$ rompendo definitivamente com a definição puramente descritiva da psiquiatria. Neste texto, vincula o surgimento da paranoia a um desejo homossexual recalcado. Assim, se por um

\footnotetext{
${ }^{1}$ Vale destacar que o termo paranoia, largamente utilizado por Freud, diz respeito à noção pré-kraepeliana do termo. Nesse momento da obra, Freud oscila entre utilizar a definição pré-kraepeliana, mais abrangente, do termo e a definição de Kraepelin, dementia paranoides, como podemos observar já no título do texto: "Notas psicanalíticas sobre um relato autobiográfico de um caso de paranoia (dementia paranoides)".
} 


\section{ARTIGOS}

lado, aparentemente a noção de paranoia como defesa de um desejo homossexual continua sendo descritiva, na medida em que se foca no conteúdo do delírio e não na estrutura do mecanismo, por outro lado, o autor rompe com a psicopatologia descritiva, na medida em que apresenta o delírio paranoico como uma tentativa de cura. "A formação delirante, que presumimos ser o produto patológico, é, na realidade, uma tentativa de restabelecimento, um processo de reconstrução" (Freud, 1911/2006e, p. 78).

Entendemos que a correlação entre paranoia e homossexualismo deva ser lida com o devido cuidado, já que é fundamental para o entendimento da posição estrutural que o paranoico ocupa em relação ao Outro. A proximidade da psicose em relação ao feminino - que Freud apresenta sob a forma de desejo homossexual, e que Lacan chamará, em 1972 em "O aturdito", de empuxo à mulher (Lacan, 1972/2003, p. 466) — deve-se ao lugar de objeto que ambos ocupariam na relação ao Outro - ainda que este lugar possa ser ocupado de formas bastante diferentes.

Na obra freudiana, chama a atenção que esta posição de objeto do paranoico já apareça marcada na inversão proposicional sugerida por Freud nesse mesmo texto de 1911. Nesta inversão, pode-se observar que o delirante passa de uma posição ativa a uma posição passiva: no delírio de perseguição, de eu o amo a ele me odeia (persegue); no delírio erotômano, de eu o amo a ela me ama e, no delírio de ciúmes, de eu o amo a ela o ama. Desta forma, seja objeto de ódio, objeto de amor ou objeto de traição, o sujeito encontra-se na posição de objeto do Outro.

Entretanto, Freud apresenta uma quarta inversão, a propósito da megalomania: inversão que "rejeita a proposição como um todo" e que seria equivalente a "eu só amo a mim mesmo" (Freud, 1911/2006e, p. 72). Nesta quarta inversão, o eu continua ocupando uma posição passiva - aquele que é amado —, mas ocupa também, concomitantemente, uma posição ativa - aquele que ama. Tal fato aponta para uma tomada de posição do sujeito ativo, ainda que identificado ao objeto.

A partir do exposto e, sobretudo, da posição de objeto que o paranoico ocupa na construção delirante, aponta-se a diferença face à fantasia delirante de Norbert, personagem de Jensen, que pode ser localizado na posição ativa, de sujeito desejante, enquanto Schreber, tal qual nosso paciente Roberto, constrói seu delírio, ao menos inicialmente, colocando-se numa posição passiva, posição de objeto do Outro. Do mesmo modo, o delírio é, para Roberto, uma tentativa de cura, uma vez que permite a ele sair, por meio da estruturação delirante, da posição de objeto passivo rumo a uma posição mais ativa.

Seguindo a obra freudiana, vale destacar que em 1914, Freud elabora sua teoria do narcisismo, retomando o que já havia anunciado no caso Schreber: que a paranoia estaria atrelada a uma fixação no estádio narcísico (de investimento libidinal no eu), explicando o caráter megalomaníaco da mesma. É assim que Freud caracteriza, em 1915, a paranoia — junto à melancolia — como uma neurose narcísica. 
Em 1924, no artigo "Neurose e psicose", Freud (1924/2006i) define o delírio como "um remendo no lugar em que originalmente uma fenda apareceu na relação do ego com o mundo externo" (p. 169). Marca, a partir disso, a diferença entre neurose e psicose exatamente no ponto em que se constrói o delírio - esta tentativa de cura que tem por objetivo reconstruir a realidade perdida. Entretanto, no mesmo ano, no artigo "Perda da realidade na neurose e na psicose", Freud (1924/2006i) afirma que esta diferença não seria tão fácil de ser estabelecida, já que a perda da realidade, assim como o substituto da realidade, existiria para ambas. E ainda acrescenta que, na psicose tal qual na neurose, haveria um conflito entre a realidade substituta e o fragmento de realidade rejeitado.

Mas, neste mesmo artigo, Freud estabelece uma diferença entre estes dois conflitos. Diferença esta que não se colocaria na segunda etapa (da substituição da realidade), mas na primeira, isto é, a fase de negação da realidade: "a neurose não repudia a realidade, apenas a ignora; a psicose a repudia e tenta substitui-la" (p. 207).

Chamamos a atenção para a importância desta diferenciação, que será retomada por Lacan em 1955-1956. Ambas possuem mecanismos de defesa análogos: um mais radical que o outro. Se na neurose há o recalque, isto é, a fuga da realidade; na psicose, há o repúdio, a rejeição, a Verwerfung, termo freudiano ${ }^{2}$ que Lacan (1955-1956) se apropriará, traduzindo-o por foraclusão.

Neste artigo, Freud observa, ainda, que as diferenças em relação à fuga ou repúdio da realidade (primeira fase) e às formas de substituto da realidade (segunda fase - fantasia ou delírio) se devem às diferenças topográficas do conflito - tal qual havia assinalado no artigo "Neurose e psicose".

Em 1937, no artigo "Construções em análise", Freud retoma ambas as diferenças assinaladas nos artigos de 1924, estabelecendo a relação entre uma e outra. Retomando o que havia sido assinalado em seu "Rascunho H", de 1895, ele traz uma analogia entre a estruturação neurótica - fantasística - e a estruturação psicótica - delirante - e afirma que em ambas haveria uma tentativa de explicação e de cura, com a diferença de que na psicose não seria possível recuperar o fragmento de experiência perdida que haveria sido rejeitado e que, portanto, o delírio portaria um elemento de verdade histórica - aquilo que se torna verdade através do tempo - inserido no lugar da realidade rejeitada.

A partir do caso clínico apresentado e desta indicação de Freud, pode-se extrair tanto o elemento de experiência perdida, que desencadeou a psicose em Roberto, quanto o elemento de verdade histórica que ele criou.

${ }^{2} \mathrm{O}$ termo Verwerfung é extraído do caso clínico "O homem dos lobos". 


\section{ARTIGOS}

O encontro com a morte vivido por Roberto, isto é, a tentativa de homicídio sofrida, tentativa de "apagá-lo", corresponde à experiência perdida que - embora tenha desencadeado o surto - não aparece em suas elaborações. Vale destacar que, nesta experiência perdida, Roberto encontrava-se em posição passiva, de objeto.

Já o apagão elétrico - no qual, segundo sua própria explicação, ele passaria a ter sido visado - pode ser entendido como o elemento de verdade histórica de seu delírio, uma vez que permite a Roberto inverter esta posição, de certo modo. É só a partir deste elemento que Roberto pode construir seu delírio e se localizar no mundo enquanto sujeito, aquele que faz chover: sujeito ativo, sob a forma de um eu engrandecido (megalomania), que pode, ou não, evitar um novo apagão - apagão aqui, em ambos os sentidos, já que, fazendo chover, ele evita, por um lado, a falta de água e energia e, por outro, evita também que as pessoas queiram "apagá-lo", isto é, matá-lo.

É neste sentido que enfatizamos a importância do delírio enquanto conceito estruturante, junto ao mecanismo de defesa psicótico, ao abordarmos a psicose enquanto estrutura clínica. Esta perspectiva permite traçar uma direção de tratamento que não se funda na simples descrição de fenômenos psicopatológicos, mas que leva em conta a posição do sujeito em relação ao Outro.

$\mathrm{Na}$ primeira fase do delírio paranoico de Schreber, ele encontra-se sozinho em um mundo insuportavelmente ameaçador, no qual não se vê investimento libidinal algum, nem em si mesmo, nem nos outros. Esse primeiro momento da construção delirante de Schreber evidencia o insuportável do encontro com o Real, assim como o radicalismo do desamparo humano, no qual, sem o laço de amor, a existência enquanto humana se torna insustentável.

Num segundo momento, o de conciliação, Schreber ainda encontra-se sozinho, excluído do laço, entretanto, constrói um mundo não tão ameaçador, no qual se evidencia um investimento libidinal em si mesmo. É o início de uma fase megalomaníaca. É espantoso, nessa fase, o quanto o caráter radicalmente fictício da realidade psíquica fica evidenciado na estruturação delirante. Aqui, o sujeito constrói um laço com o Outro, sustentando sua existência. Um laço, entretanto, não partilhado, o que acarreta, paradoxalmente, uma dificuldade de inserção no laço social. Se chamamos a atenção para o paradoxo que há nessa construção delirante, é que, apesar de não partilhada, é ela que dá condições a Schreber de lutar por sua saída do asilo manicomial e pela restituição de seus direitos civis. Dessa forma, esse investimento libidinal em si mesmo mostra-se importantíssimo na empreitada da tentativa de cura que o paranoico traça para si.

Observa-se, portanto, que o delírio vem para dar consistência ao irrepresentável. Freud (1915/2006g) nos diz que o esquizofrênico faz um investimento libidinal em palavras por não podê-lo fazer em coisas. As invenções delirantes vêm para dar consistência ao que acomete o sujeito. E precisam ser ouvidas, ao pé da letra, como diz Lacan (1954-1955/1985). 


\section{O delírio como tentativa de restabelecimento de um ideal}

A entrada de Lacan na psicanálise faz-se a partir de um caso de paranoia, o "Caso Aimée", apresentado em sua tese de doutorado. Sua tese chama a atenção pela dedicação a um único caso, ao longo de todo o trabalho. Nela, Lacan nos apresenta a história e a construção delirante de Marguerite (nome original de Aimée), internada no Hospital psiquiátrico de Sainte Anne após ser presa por um atentado a uma atriz.

Em Paranoia: Marguerite ou a Aimée de Lacan, Jean Allouch (1997) revisita o caso Aimée (Lacan, 1932/1987) a partir de um saber formalizado posteriormente pelo próprio Jacques Lacan. Com a estrutura da foraclusão e a noção dos fenômenos elementares como retorno do foracluído, Allouch nos apresenta uma segunda versão da tese, versão latente na própria apresentação do caso, que localiza em Marguerite o empuxo ao assassinato do filho, empuxo este localizado, pela paciente, no Outro do delírio.

Marguerite tem seu sistema delirante girando em torno da ameaça de assassinato de seu filho, assim como das acusações a ela dirigidas, por ter seu jardim secreto revelado. Entretanto, Marguerite indica claramente que, se ameaçavam seu filho, era por sua culpa.

Assim, embora a perseguição ocorra em torno de seu filho é, desde o início, ela mesma o objeto-alvo deste Outro indeterminado que a condena.

A partir deste caso é possível apreender que é no desarranjo imaginário da imagem do eu do sujeito, em relação à sua imagem ideal, que o desencadeamento paranoico pode ser localizado, assim como, que a estruturação delirante visa o restabelecimento deste arranjo.

Na tese lacaniana, a irmã mais velha de Aimée é considerada seu duplo especular por ser boa mãe, esposa ideal, ou seja, tudo que ela almejaria ser, sem, no entanto, conseguir. Seria essa irmã a verdadeira perseguidora, ainda que não declarada. A atriz, a qual Aimée ataca em sua passagem ao ato, também é considerada seu duplo, entrando na série dos perseguidores. Porém, observa-se que essa atriz está em uma outra vertente, diferente da irmã: a da mulher depravada. A atriz parece ser não seu ideal, mas aquilo exatamente que Aimée não gostaria de ser acusada de ser, aquilo que considera estranho a ela mesma, embora evidencie, em suas acusações, ser familiar. Portanto, entendemos haver, aqui, uma identificação que, estando foracluída, retorna no real, como um saber que pertence ao Outro.

Freud (1933/1987), em sua carta a Lacan, chama a atenção para o conflito existente nas formações do inconsciente de caráter autopunitivas: o formador do sonho, ou, no caso, do ato, não seria um desejo inconsciente, ou seja, um desejo do sujeito, mas um desejo punitivo do supereu. O supereu, entretanto, sendo ainda arcaico, como o é na psicose, retorna no real. 


\section{ARTIGOS}

Huguete ex-Duflos, atriz atacada, representava as peças de Pierre Benoit, um romancista acusado por Marguerite de revelar, pelos seus escritos, a conduta anterior de Marguerite. Diversos jornais da época teriam revelado que um dos maiores receios da paciente era o de que seu marido, René Anzieu, a reconhecesse nos romances. Seu marido leria nas entrelinhas do romance "suas confissões e suas vergonhas" (Allouch, 1997, p. 167). Marguerite "sente-se ultrajada com o fato de que ele divulgue uma certa verdade que ela reconhece como sua" (Ibid.).

A erotomania, assim como as ideias de grandeza, apontam, então, vir em contraponto ao delírio de perseguição, no sentido de restabelecer a imagem de uma mulher pura, dessexualizada.

A passagem ao ato tem a função de defendê-la de tal acusação, dizendo, em sua face significante, aquilo que não foi possível ser dito em palavras - embora não se possa dizer que ela não tenha tentado: Marguerite bem que tentou publicar seus romances, os quais tinham um estatuto de réplica àqueles escritos por Pierre Benoit.

$\mathrm{O}$ atentado à Huguete ex-Duflos parece afirmar, em ato, Marguerite não como mulher, mas como mãe, apaziguando de alguma forma aquilo de que ela se sentia acusada anteriormente, ou seja, de ser uma mãe "vil", "criminosa" (Lacan, 1932/1987, p. 160). É assim, protegendo seu filho, que Marguerite afirma, em ato, o contrário daquilo de que se sente acusada pelo Outro: de ser uma mãe criminosa.

O significante puta é atrelado a uma determinada forma de gozo, um gozo proibido. E é o que "acusavam" Marguerite de ser. O significante mãe, de um modo análogo, é atrelado a outro modo de gozo, desta vez melhor aceito no laço social, e é como ela luta para ser reconhecida. Na paranoia, entretanto, o conflito psíquico decorrente dessa atribuição de saber sobre o gozo aparece a céu aberto, sem dialetização: não há um sujeito que se divide, mas um eu e um Outro.

Com Roberto, caso apresentado no início deste trabalho, há, por um lado, o atrelamento ao significante "malandro", aquilo de que ele sente-se acusado pelo Outro de ser; em contraposição, forma-se, com a construção delirante, um outro significante, Santo Roberto, aquele que faz chover. É a partir deste outro significante que o gozo do Outro pode ser minimamente apaziguado para Roberto.

\section{Considerações finais}

A abordagem freudiana em torno do delírio foi fundamental para apreender o delírio enquanto um fenômeno estruturado, tendo uma função para o sujeito. Com 
a construção delirante, tentativa de cura, o sujeito pode se localizar no mundo, por meio de uma organização significante, ainda que não partilhada. A verdade transmitida pelo sujeito pelo delírio, que Freud denomina verdade histórica, encontra meios de ser abordada, e até mesmo tratada pelo significante.

Com Lacan, a estruturação delirante - como ele a chama - fica ainda mais evidente. É a partir de uma defasagem entre a imagem do eu e a imagem do ideal que uma eclosão da psicose pode ocorrer. E a construção delirante, como vimos com Aimée, visa restabelecer uma correlação entre o eu e o ideal. Em alguns momentos, o paciente pode chegar a deixar de lado o seu delírio, como acontece com Aimée e também com Roberto. Entretanto, isso não significa que o delírio foi abandonado. Entendemos que esse desinvestimento no delírio é mais a consequência de uma estabilização que sua causa, o que acontece para além, e não aquém, da construção delirante.

Dessa forma, diferente dos manuais psiquiátricos contemporâneos (APA, 2002; OMS, 1993), que relatam o delírio quase como que uma entidade à parte do sujeito, é importante lembrar que há um sujeito por trás disso, e que é preciso ouvir o delírio, ainda que sem interpretá-lo, tomando-o ao pé da letra. Lembra-se ainda que é preciso que essa escuta seja pautada pela ética da psicanálise, aquela que aponta para o impossível do objeto (Lacan, 1959-1960/1997). Entretanto, como nos lembram Soler (2008) e Zenoni (2000), na psicose, é preciso que essa impossibilidade seja indicada no Outro. Assim, não é o sujeito que fica impossibilitado de identificar-se a essa imagem ideal, o que poderia acarretar uma desestabilização, mas o acesso ao objeto como impossível ao Outro que deve ser evidenciado. O limite, a castração, dessa forma, é indicado, não no próprio sujeito, mas no Outro.

\section{Referências}

Allouch, J. (1997). Paranoia: Marguerite ou A “Aimée” de Lacan. Rio de Janeiro: Companhia de Freud.

Associação Psiquiátrica Americana (APA). (2000). Manual Diagnóstico e Estatístico de Transtornos Mentais (DSM-IV-TR). (4 edição - Revista). Porto Alegre: Artmed, 2002.

Bercherie, P. (1989). Os fundamentos da clínica. Rio de Janeiro: Jorge Zahar.

Berrios, G. E.; Diego, F. F. (1996). Delírio: história, clínica, metateoria. Madrid: Trotta.

Berrios, G. E. (2006). The history of Mental Symptoms: descriptive psychopathology since the nineteenth century. New York: Cambridge University Press.

Berrios, G. E. (2011, mar.). Delirium e confusão mental no século XIX: uma história conceitual. Revista Latinoamericana de Psicopatologia Fundamental, São Paulo, 14(1), 166-189. 


\section{ARTIGOS}

Dalgalarrondo, P. (2008). Psicopatologia e semiologia dos transtornos mentais. Porto Alegre: ArtMed.

Ey, H. (1974). Manual de psiquiatria. Rio de Janeiro: Atheneu.

Foucault, M. (2005). História da loucura. São Paulo: Perspectiva. (Trabalho original publicado em 1987).

Freud, S. (2006a). Prefácio e notas de rodapé à tradução das Conferências das terças-feiras, de Charcot [1892-1894]. In Edição Standard Brasileira das Obras Psicológicas Completas de Sigmund Freud (v. I). Rio de Janeiro: Imago. (Trabalho original publicado em 1892-1894).

Freud, S. (2006b). A interpretação dos sonhos. In Edição Standard Brasileira das Obras Psicológicas Completas de Sigmund Freud (v. IV e V). Rio de Janeiro: Imago. (Trabalho original publicado em 1900).

Freud, S. (2006c). Três ensaios sobre a teoria da sexualidade. In Edição Standard Brasileira das Obras Psicológicas Completas de Sigmund Freud (v. VII). Rio de Janeiro: Imago. (Trabalho original publicado em 1905).

Freud, S. (2006d). Delírios e sonhos na Gradiva de Jensen. In Edição Standard Brasileira das Obras Psicológicas Completas de Sigmund Freud (v. XII). Rio de Janeiro: Imago. (Trabalho original publicado em 1907).

Freud, S. (2006e). Notas psicanalíticas de um relato autobiográfico de um caso de paranoia. In Edição Standard Brasileira das Obras Psicológicas Completas de Sigmund Freud (v. XII). Rio de Janeiro: Imago. (Trabalho original publicado em 1911).

Freud, S. (2006f). Sobre o narcisismo: uma introdução. In Edição Standard Brasileira das Obras Psicológicas Completas de Sigmund Freud (v. XIV). Rio de Janeiro: Imago. (Trabalho original publicado em 1914).

Freud, S. (2006g). Os instintos e suas vicissitudes. In Edição Standard Brasileira das Obras Psicológicas Completas de Sigmund Freud (v. XIV). Rio de Janeiro: Imago. (Trabalho original publicado em 1915).

Freud, S. (2006h). O inconsciente. In Edição Standard Brasileira das Obras Psicológicas Completas de Sigmund Freud (v. XIV). Rio de Janeiro: Imago. (Trabalho original publicado em 1915).

Freud, S. (2006i). A perda da realidade na neurose e na psicose. In Edição Standard Brasileira das Obras Psicológicas Completas de Sigmund Freud (v. XIX). Rio de Janeiro: Imago. (Trabalho original publicado em 1924).

Freud, S. (2006j). Neurose e psicose. In Edição Standard Brasileira das Obras Psicológicas Completas de Sigmund Freud (v. XIX). Rio de Janeiro: Imago. (Trabalho original publicado em 1924[1923]).

Freud, S. (2006k). Construções em análise. In Edição Standard Brasileira das Obras Psicológicas Completas de Sigmund Freud (v. XXIII). Rio de Janeiro: Imago. (Trabalho original publicado em 1937).

Freud, S. Carta de Freud a Lacan (1933). In Roberto, H. Discorrer a psicanálise. São Paulo: Artes Médicas, 1987.

Lacan, J. (1985). O seminário. Livro 1. O eu na teoria de Freud e na técnica da psicanálise. Rio de Janeiro: Jorge Zahar. (Trabalho original publicado em 1954-1955). 
Lacan, J. (1987). Da psicose paranoica em suas relações com a personalidade. Rio de Janeiro: Forense-Universitária. (Trabalho original publicado em 1932)

Lacan, J. (1997). O seminário. Livro 7. A ética da psicanálise. Rio de Janeiro: Jorge Zahar. (Trabalho original publicado em 1959-1960)

Lacan, J. (1998). Formulações sobre a causalidade psíquica. In Escritos. Rio de Janeiro: Jorge Zahar. (Trabalho original publicado em 1959-1960)

Lacan, J. (2002). O seminário. Livro 3. As psicoses. Rio de Janeiro: Jorge Zahar. (Trabalho original publicado em 1955-1956)

Lacan, J. (2003). O aturdito. In Outros escritos (pp. 448-497). Rio de Janeiro: Jorge Zahar. (Trabalho original publicado em 1972)

Maleval, J.-C. (1998). Lógica del delírio. Barcelona: Ediciones Del Serbal.

Organização Mundial de Saúde - OMS (1993). Classificação de Transtornos Mentais e de Comportamento da CID-10. Porto Alegre: Artmed.

Soler, C. (2008). Que lugar para el analista? In Estudios sobre las psicosis. Buenos Aires: Manantial.

Zenoni, A. (2000). Qual instituição para o sujeito psicótico? Abrecampos, [S. 1.], 1(0), 12-31, jun. 2000.

\section{Resumos}

(The psychotic subject and the function of delusions)

This paper examines the concept of delusion and its function in the psychotic structure. Psychoanalysis considers delusions, on the one hand, as elementary phenomena and, on the other, as realities to be treated through truth. Here we address the delusional structure and its function in the paranoid subject, in order to determine the direction of treatment for the patient. We take a clinical case and, based on psychoanalytic concepts, discuss the function of delusion for the subject. The invention of the subject is considered beyond delusion, based on a point of stabilization, and occurring without the delusion.

Key words: Delusion, paranoia, direction of treatment

\section{(Le sujet et la fonction du délire)}

Cet article aborde le concept du délire et sa fonction dans la structure psychotique. La psychanalyse considère le délire d'une part comme un phénomène élémentaire et d'autre part comme une tentative de guérison, porteur d'une vérité. Nous abordons la structure délirante et sa fonction par rapport au sujet paranoïaque afin de définir la gestion du traitement de la clinique de la paranoïa. A partir d'un cas clinique, en prenant comme base les concepts de la psychanalyse, nous discutons la fonction du délire pour le 


\section{ARTIGOS}

sujet. Nous prenons en compte l'invention du sujet au-delà du délire, à partir d'une stabilisation qui, cependant, n'a pas lieu sans celui-ci.

Mots clés: Délire, paranoïa, gestion du traitement

(El sujeto psicótico y la función del delirio)

El presente artículo aborda el concepto de delirio y su función en la estructura psicótica. El Psicoanálisis considera el delirio, por un lado, como un fenómeno elemental y, por otro, como una tentativa de curación, portadora de una verdad. Este trabajo tiene como objetivo abordar la estructura delirante, así como su función para el sujeto paranoico, con el objetivo de ubicar la dirección de tratamiento en la clínica de la paranoia. Partiendo de un caso clínico y basándose en los conceptos del psicoanálisis, se discute la función del delirio para el sujeto. Se tiene en cuenta la invención del sujeto para más allá del delirio a partir de una estabilización, que, sin embargo, no acontece sin él.

Palabras clave: Delírio, paranoia, dirección de tratamiento

\section{(Das Subjekt und die Funktion des Deliriums)}

In dieser Untersuchung wird der Begriff "Delirium" und seine Funktion in der psychotischen Struktur behandelt. Einerseits wird Delirium in der Psychoanalyse als elementares Phänomen betrachtet; andererseits als Heilungsversuch und Träger einer Wahrheit. Ziel der vorliegenden Untersuchung ist, die zum Delirium führende Strukturierung sowie deren Funktion für die paranoische Person zu betrachten, um die Behandlungsrichtung in der psychiatrischen Klinik zu bestimmen. Ausgehend von einem empirischen Fall und aufgrund der psychoanalytischen Konzepte wird die Funktion desselben für das Subjekt besprochen. Dabei werden die Erfindungen des Subjektes über die Wahnvorstellungen hinaus mit in Betracht gezogen, ab einer gewissen Stabilisierung, die sich jedoch nicht ohne Mitwirkung des Subjektes ergibt.

Schlüsselwörter: Delirium, Paranoia, Behandlungsrichtung

Citação/Citation: Briggs, R. \& Rinaldi, D. (2014, setembro). O sujeito psicótico e a função do delírio. Revista Latinoamericana de Psicopatologia Fundamental, 17(3), 416-430.

Editor do artigo/Editor: Manoel Tosta Berlinck

Recebido/Received: 5.9.2013/ 9.5.2013 Aceito/Accepted: 8.11.2013 / 11.8.2013 
Copyright: (C) 2009 Associação Universitária de Pesquisa em Psicopatologia Fundamental/ University Association for Research in Fundamental Psychopathology. Este é um artigo de livre acesso, que permite uso irrestrito, distribuição e reprodução em qualquer meio, desde que o autor e a fonte sejam citados / This is an open-access article, which permits unrestricted use, distribution, and reproduction in any medium, provided the original authors and sources are credited.

Financiamento/Funding: As autoras declaram não ter sido financiadas ou apoiadas / The authors have no support or funding to report.

Conflito de interesses/Conflict of interest: As autoras declaram que não há conflito de interesses / The authors declare that has no conflict of interest.

\section{RAQUel BRIGGS}

Psicóloga; Psicanalista; Doutoranda e Mestre em Pesquisa e Clínica em Psicanálise pela Universidade do Estado do Rio de Janeiro - UERJ (Rio de Janeiro, RJ., Br); Especialista em Dependência Química pela Universidade Federal de São João del Rei (São João del Rei, MG, $\mathrm{Br})$.

Av. Francisco Vieira Martins, 595/204

35430-226 Ponte Nova, MG, Br

e-mail: rcbalbuquerque@yahoo.com.br

\section{Doris Rinaldi}

Psicanalista; Doutora em Antropologia Social pela Universidade Federal do Rio de Janeiro - UFRJ (Rio de Janeiro, RJ, Br); Professora Assistente do Instituto de Psicologia da Universidade do Estado do Rio de Janeiro - IP/UERJ (Rio de Janeiro, RJ, Br); atuando no Programa de Pós-Graduação em Psicanálise do IP/UERJ; Procientista - UERJ; bolsista do Conselho Nacional de Desenvolvimento Científico e Tecnológico - CNPq (Brasília, DF, Br); psicanalista membro de Intersecção Psicanalítica do Brasil (Rio de Janeiro, RJ, Br).

Travessa Mário de Castro, 97 - Botafogo

22280-130 Rio de Janeiro, RJ, Br

e-mail: doris@uerj.br / doris_rinaldi@yahoo.com.br 